\title{
Processing and structural properties of random oriented lead lanthanum zirconate titanate thin films
}

\author{
E. B. Araújo ${ }^{1 *}$, B. O. Nahime ${ }^{1}$, M. Melo ${ }^{1}$, F. Dinelli ${ }^{2}$, F. Tantussi ${ }^{2,3}$, \\ P. Baschieri ${ }^{2}$, F. Fuso ${ }^{2,3}$ and M. Allegrini ${ }^{2,3}$ \\ ${ }^{1}$ Faculdade de Engenharia de Ilha Solteira, UNESP - Univ Estadual Paulista, Departamento \\ de Física e Química, 15385-000 Ilha Solteira, SP, Brazil \\ ${ }^{2}$ CNR, INO UOS A Gozzini, Area Ric Pisa S Cataldo, I-56124 Pisa, Italy \\ ${ }^{3}$ Univ Pisa, Dipartimento Fis Enrico Fermi, I-56127 Pisa, Italy
}

\begin{abstract}
Polycrystalline lead lanthanum zirconate titanate (PLZT) thin films have been prepared by a polymeric chemical route to understand the mechanisms of phase transformations and map the microstructure and elastic properties at the nanoscale in these films. X-ray diffraction, Atomic Force Microscopy (AFM) and Ultrasonic Force Microscopy (UFM) have been used as investigative tools. On one side, PLZT films with mixed-phase show that the pyrochlore phase crystallizes predominantly near the bottom film-electrode interface while a pure perovskite phase crystallizes in top film surface. On the contrary, pyrochlorefree PLZT films show a non-uniform microstrain and crystallite size along the film thickness with a heterogeneous complex grainy structure leading to different elastic properties at nanoscale.
\end{abstract}

Keywords: thin films; chemical synthesis; atomic force microscopy.

\footnotetext{
* Corresponding author: eudes@dfq.feis.unesp.br Fax: +55 18 3742-4868
} 


\section{Introduction}

The lead lanthanum zirconate titanate, $(\mathrm{Pb}, \mathrm{La})(\mathrm{Zr}, \mathrm{Ti}) \mathrm{O}_{3}$ (referred as $\left.\mathrm{PLZT}\right)$, is known to exhibit remarkable dielectric, piezoelectric and electro-optic properties [1,2]. Depending on the $\mathrm{Zr} / \mathrm{Ti}$ ratio and $\mathrm{La}$ amount in the PLZT system, the material reveals a relaxor behavior giving rise to very large dielectric constants, electro-mechanical and electrooptical coefficients [3]. The composition $\mathrm{La} / \mathrm{Zr} / \mathrm{Ti}=9 / 65 / 35 \mathrm{~mol} \%$ is particularly important because most of the properties of technological interest show their maximum values at this ratio [4]. In the thin film form, the great potential of the PLZT system has been demonstrated in the past years for applications in capacitors [5], nonvolatile ferroelectric random memories [6], waveguide [7], and others.

PLZT thin films can be deposited by various methods, such as pulsed laser deposition PLD [8], sol-gel [9], rf-sputtering [10], and others. Sol-gel technique is the most convenient method due to low cost, high control of the composition and high degree of homogeneity of the films. The kinetic of the perovskite phase transformation in PLZT thin films has been studied in details for films deposited by the different methods. In general, the crystallization of PLZT films using chemical routes is similar to the $\mathrm{Pb}(\mathrm{Zr}, \mathrm{Ti}) \mathrm{O}_{3}(\mathrm{PZT})$ system [11] and, starting from the amorphous structure, it first transforms into an intermediate nonferroelectric phase and then into the perovskite phase after an adequate pyrolysis and thermal annealing [12]. Often described as pyrochlore, sometimes also referred as $\mathrm{Pb}$ deficient fluorite phase [12], the non-ferroelectric phase forms during the film crystallization due to slight deviations from the nominal stoichiometry as a consequence of the $\mathrm{PbO}$ volatilization. The pyrochlore phase is usually described as cation-ordered structure while the absence of ionic ordering is related to the fluorite structure [13]. In the present work, we will use the term pyrochlore for the secondary non-ferroelectric phase. 
The presence of the pyrochlore phase degrades the most important physical properties of $\mathrm{Pb}$-based ferroelectric thin films. Then, to fabricate high-quality thin films for an eventual use in integrated devices, the control and suppression of the pyrochlore phase during the preparation are essentials. Reducing the processing temperatures or adding excess of $\mathrm{PbO}$ to compensate the $\mathrm{Pb}$-loss are the traditional alternatives to suppress the pyrochlore phase in ferroelectric films. In addition, the pyrolysis temperature and postpyrolysis treatments are fundamental parameters to control the nucleation and perovskite growth in thin films produced by chemical routes. Recent studies on the transformation of pyrochlore phase in PLZT thin films show that the subject remains open to discussions [12].

Herein we present PLZT thin films prepared by an alternative technique to the conventional ones. Main goals of the present paper is to study the perovskite phase transformation and the suppression of the pyrochlore phase which can be successfully achieved in the films and have not been so far the subject of systematic investigations for films prepared by the mentioned technique.

\section{Experimental}

PLZT thin films with $\left(\mathrm{Pb}_{0.91} \mathrm{La}_{0.09}\right)\left(\mathrm{Zr}_{0.65} \mathrm{Ti}_{0.35}\right) \mathrm{O}_{3}$ nominal composition have been prepared using a chemical route. The general idea is the modification of the Pechini [14] method to prepare a polymeric resin, to deposit it onto a substrate and then crystallize the perovskite phase under adequate heat annealing. The modification introduced in Pechini method is based on the fact that not all used precursor oxides $\left(\mathrm{PbO}, \mathrm{La}_{2} \mathrm{O}_{3}, \mathrm{ZrO}_{2}\right.$ or $\left.\mathrm{TiO}_{2}\right)$ are soluble in acid media, but only the reacted complex PLZT oxide is soluble. Then, it is

possible to use the PLZT powder to prepare the precursor polymeric solution instead of 
metalorganic alkoxide or carboxylate as usual starting reagents. Then, the PLZT powder with $10 \mathrm{~mol} \%$ of lead in excess can be prepared by the conventional solid-state reaction using commercial reagents $\mathrm{PbO}$ (Synth, 98\%), $\mathrm{La}_{2} \mathrm{O}_{3}$ (Aldrich, 99.99\%), $\mathrm{TiO}_{2}$ (Aldrich, 99\%) e $\mathrm{ZrO}_{2}$ (Aldrich, 99\%). The mixed oxides are calcined in two steps, at $850{ }^{\circ} \mathrm{C}$ for 3.5 hours and then at $1100{ }^{\circ} \mathrm{C}$ for 3.5 hours. At room temperature, a high quality PLZT powder (stoichiometric and free of secondary phases) is obtained and ready to be used as starting precursor to prepare the polymeric resin.

To prepare the stoichiometric polymeric resin, PLZT powder $(100 \mathrm{mg})$ is dissolved in $50 \mathrm{~mL}$ of nitric acid solution $\left(10 \%\right.$ of $\mathrm{HNO}_{3}$ and $90 \%$ of $\left.\mathrm{H}_{2} \mathrm{O}\right)$ at $80^{\circ} \mathrm{C}$ during 1 hour. After the complete dissolution and adding distilled water, $\sim 30 \mathrm{~mL}$ of a clean and transparent stock solution is obtained at room temperature. Next, citric acid (CA) is added to the stock solution $(\mathrm{CA} /$ metal molar ratio equal to 15$)$ to form a metallic ions citrate heating and stirring this mixture at $90^{\circ} \mathrm{C}$ for $50 \mathrm{~min}$. When the volume of this solution reaches $\sim 5 \mathrm{~mL}$, ethylene glycol (EG) is added to the solution (CA/EG mass ratio equal to 60/40) maintaining the mixture under heating and stirring at $90{ }^{\circ} \mathrm{C}$ for 20 minutes to complete the polymerization of the stoichiometric resin. To compensate the loss of lead during the film preparation and to stabilize the growth of the perovskite phase, a second resin is prepared dissolving $0.0126 \mathrm{~g}$ of $\mathrm{PbO}$ in $10 \mathrm{~mL}$ of nitric acid solution at $80^{\circ} \mathrm{C}$ during 10 minutes. The amount of $\mathrm{PbO}$ in the second resin represents $20 \mathrm{~mol} \%$ in excess of the nominal composition of PLZT in the first resin. The second resin is prepared following the same procedures of the first one. Finally, the two resins are mixed at room temperature and stirred during 1 hour for homogenization. After the complete homogenization, the final transparent resin $(\sim 15 \mathrm{~mL})$ is ready to start the film depositions. This procedure is 
necessary, since introducing the $\mathrm{PbO}$ excess directly in the PLZT powder leads to unstable resins that precipitates within some days after the preparation.

Films of polymeric resins are initially deposited by spin coating on $\mathrm{Pt} / \mathrm{Ti} / \mathrm{SiO}_{2} / \mathrm{Si}(100)$ substrates at $6000 \mathrm{rpm}$ for 20 seconds. The pyrolysis is performed in air putting the deposited films directly on a hot plate at $\sim 200{ }^{\circ} \mathrm{C}$ for $5 \mathrm{~min}$ and then in an electric furnace at $300{ }^{\circ} \mathrm{C}$ for 1 hour. The film thickness increases with depositing a new layer on the previous pyrolyzed film and repeating the same heat annealing procedure to remove the organics. After obtaining the required film thickness, a final heat annealing in conventional electric furnace at $700{ }^{\circ} \mathrm{C}$ for 1 hour promotes the film crystallization. The final films are uniform and crack-free with thicknesses between $238-540 \mathrm{~nm}$.

X-ray diffraction (XRD) technique has been used to study the structural properties of the PLZT films using a Rigaku Ultima IV diffractometer with $\mathrm{CuK}_{\alpha}(\lambda=1.5406 \AA)$ radiation. Additionally, the films structure in depth profile has been studied by using XRD measurements at room temperature in step scan mode at the grazing incidence $\theta$ angle configuration $\left(2^{\circ} \leq \theta \leq 6^{\circ}\right)$ scanning the $2 \theta$ angle from $20^{\circ}$ to $60^{\circ}$. The Williamson-Hall [15] analysis has been applied to evaluate the microstrain $(\Delta d / d)$ and crystallite size $(D)$ of the PLZT films according to $\Gamma \cos \theta=\lambda / D+(\Delta d / d) 4 \operatorname{sen} \theta$, where $d$ is the lattice spacing, $\Gamma$ is the full width at half maximum (FWHM) value due to peak broadening, $\lambda$ is the wavelength and $\theta$ is the Bragg angle.

The Atomic Force Microscope (AFM) used in the present work is a setup made of a commercial head (NT-MDT, Smena), with electronics and software for control and acquisition developed in our laboratories. The cantilevers used for this work are rectangular silicon ones with stiffness constant between 0.1 and 1 N/m (CSCS12, NT-MDT). 
Ultrasonic Force Microscopy (UFM) is operated at $4 \mathrm{MHz}$, while the amplitude is modulated at $4 \mathrm{kHz}$, by means of a piezo-plate located directly under the sample [16] and driven by a function generator (Agilent 33220A). The maximum displacement amplitude is less than $1 \mathrm{~nm}$ [17]. Additionally, to collect the UFM data a digital lock-in amplifier (Zurich, HF2LI) is employed. The color codes of the images are the following: topography, brighter for higher regions; UFM, brighter for higher elastic modulus.

\section{Results and discussion}

Fig. 1 summarizes the grazing incidence XRD patterns of the PLZT thin films prepared from the $\mathrm{Pb}$-stoichiometric resin. Recorded at a fix glancing angle $\theta=13^{\circ}$ and between $27.5^{\circ} \leq 2 \theta \leq 46.5^{\circ}$, the XRD patterns for the films prepared under pyrolysis at $300^{\circ} \mathrm{C}$, $350^{\circ} \mathrm{C}$ and $400^{\circ} \mathrm{C}$ for 30 minutes and crystallized at $700{ }^{\circ} \mathrm{C}$ for 1 hour are shown in Fig. 1a, $1 \mathrm{~b}$ and $1 \mathrm{c}$, respectively. In these figures, the (110) reflection refers to the perovskite PLZT phase while the peak observed at around $2 \theta=29.5^{\circ}$ is attributed to the pyrochlore phase. This result suggests a pyrochlore phase with an $\mathrm{A}_{2} \mathrm{~B}_{2} \mathrm{O}_{7}$ structure, with the $\mathrm{Ti}$ and $\mathrm{Zr}$ ions able to occupy the B-site in the pyrochlore structure to form a stable $\mathrm{Pb}_{2}(\mathrm{Zr}, \mathrm{Ti})_{2} \mathrm{O}_{7-\mathrm{x}}$ structure [18]. The differences observed in the relative intensities of the perovskite and pyrochlore peaks indicate a strong crystallization dependence on the pyrolysis temperature. Based on the peak evolution, the amount of pyrochlore phase prevails on the perovskite one for the film pyrolyzed at $400{ }^{\circ} \mathrm{C}$ (Fig. 1c). At lower pyrolysis temperature, the pyrochlore phase tends to disappear but the shoulder observed in the XRD shown in Fig. 1a is an indication that the pyrochlore phase persists in the final film. 
The formation of secondary pyrochlore phases, or fluorite phases, is a typical problem in complex Pb-based thin films (PZT or PLZT). Among the different approaches in the literature, the suppression of the pyrochlore phases can be obtained most commonly by reducing the processing temperatures to minimize the $\mathrm{PbO}$ volatility [19] or by introducing a $\mathrm{PbO}$ excess in the precursor solution to control the $\mathrm{Pb}$ stoichiometry in the final film [20]. Alternatively, to obtain a single perovskite phase a $\mathrm{PbO}$ overcoat can be placed on the amorphous film after pyrolysis to compensate the $\mathrm{PbO}$ loss from the films surface during the crystallization [12]. However, several works have demonstrated that reducing the processing temperatures is not sufficient to eliminate the presence of pyrochlore or fluorite phases on the films [13], since there are conditions favorable to the pyrochlore phase growth that do not depend only on the $\mathrm{Pb}$ loss due to the high processing temperatures. The $\mathrm{Pb}$ diffusion into $\mathrm{Pt}$ bottom electrode is an example of a factor that does not depend on the processing temperature but contributes to the loss of $\mathrm{Pb}$ in the film leading to favorable conditions for the pyrochlore phase growth.

Under specific conditions of heat treatment, the diffusion of $\mathrm{Pb}$ in thin films leads to the formation of a metastable $\mathrm{PbPt}_{\mathrm{x}}$ phase on the $\mathrm{Pt}$ substrate. The thin $\mathrm{PbPt}_{\mathrm{x}}$ interlayer formed between the film-electrode have been considered responsible of one of the possible mechanisms to produce PZT thin films with strong (111) texture [21,22]. On the other hand, films with (100) texture can be nucleated by a $\mathrm{PbO}$ layer formed on the substrate during the diffusion process. The crystallization of the cubic $\mathrm{PbPt}_{\mathrm{x}}$ phase can be confirmed by a well-defined reflection at around $2 \theta=38.5^{\circ}$ in the XRD patterns $[18,22]$. However, the absence of peaks associated to the $\mathrm{PbPt}_{\mathrm{x}}$ phase in XRD patterns shown in Fig. 1a, 1b and 1c excludes the formation of this phase in our PLZT films. In addition, crystalline 
reflections associated to a possible $\mathrm{PbO}$ layer in our films are also not observed. The used $\mathrm{Pt}(111)$ substrate and the absence of the $\mathrm{PbPt}_{\mathrm{x}}$ and $\mathrm{PbO}$ interfacial crystalline layers suggest that the nucleation is possibly governed by the substrate. Given these considerations, we suppose that nuclei initially form at the film-substrate interface but the orderly growth does not occur through the film thickness due to inhomogeneities in the structure to form randomly oriented PLZT films.

The pyrolysis temperature and post-pyrolysis treatments in oxygen are fundamental parameters to infer about the nature of the pyrochlore phase and eventually suppress its growth in $\mathrm{Pb}$-based thin films. In general, the stable $\mathrm{Pb}_{2}(\mathrm{Zr}, \mathrm{Ti})_{2} \mathrm{O}_{7-\mathrm{x}}$ pyrochlore form is $\mathrm{Pb}$ deficient while the metastable $\mathrm{Pb}_{2}(\mathrm{Zr}, \mathrm{Ti})_{2} \mathrm{O}_{6}$ is $\mathrm{Pb}$-rich [23]. In PZT thin films prepared by sol-gel, the observed $\mathrm{Pb}_{2}(\mathrm{Zr}, \mathrm{Ti})_{2} \mathrm{O}_{6}$ rapidly transforms into the perovskite phase while the stable pyrochlore phase is retained at the film surface [23]. For PZT thin films prepared by the same method used in the present work, we have already demonstrated that increasing the pyrolysis temperature the perovskite phase shift toward Ti-rich composition in comparison to the nominal composition leading to $\mathrm{Zr}$-rich and $\mathrm{Pb}$-deficient $\mathrm{Pb}_{2}\left(\mathrm{Zr}_{1-\mathrm{x}} \mathrm{Ti}_{\mathrm{x}}\right)_{2} \mathrm{O}_{6}$ pyrochlore phase, while at lower pyrolysis temperature the pyrochlore phase can transform into the perovskite phase [11]. Therefore, based on these considerations, the evolution of the pyrochlore phase observed in Fig. $1 \mathrm{a}, 1 \mathrm{~b}$ and $1 \mathrm{c}$ suggests that a stable $\mathrm{Pb}_{2}(\mathrm{Zr}, \mathrm{Ti})_{2} \mathrm{O}_{7-\mathrm{x}}$ forms in the films instead of a metastable $\mathrm{Pb}_{2}(\mathrm{Zr}, \mathrm{Ti})_{2} \mathrm{O}_{6}$ structure, since it is expected that metastable phase transforms into the perovskite one by increasing the pyrolysis temperature. Probably, the diffusion of $\mathrm{Pb}$ into the substrate promotes a deviation in stoichiometry of PLZT near the bottom film-substrate interface yielding a kinetically more favorable situation for the pyrochlore $\mathrm{Pb}$-deficient growth. 
A comprehensive study of Polli et al. [24] on the metastability of the fluorite and pyrochlore phases in the PZT system has shown that the stability of the metastable fluorite phase depends strongly of $\mathrm{ZrO}_{2}$ content and that the absence of fluorite for compositions with lower $\mathrm{ZrO}_{2}$ content suggests that perovskite phase may form directly from the amorphous structure. Although this study has provided valuable information about the phase evolution in PZT powders produced from alkoxide precursors, the experience has shown that the crystallization kinetics can be significantly different in thin films, since other factors such as film-substrate interface, stoichiometry control, $\mathrm{PbO}$ volatilization and others can strongly affect the phase transformation in Pb-based thin films [12]. With respect to the present work, Fig. 1d shows more closely the evolution of the XRD patterns at different glancing angle $\theta$ for the PLZT film pyrolyzed at $400^{\circ} \mathrm{C}$ for 30 minutes, where both pyrochlore and perovskite phases are present. We observe that the mixed-phase is clear at highest glancing angle $\theta$ and that the peak around $2 \theta=29.5^{\circ}$ disappears for $\theta$ smaller than $9^{\circ}$, a clear indication that the pyrochlore phase crystallizes predominantly near the bottom film-electrode interface and disappears at the surface.

Mapping PLZT thin films in depth profile has demonstrated that the perovskite phase nucleates first at the bottom electrode and crystallizes a mixture of perovskite and fluorite phases with a surface of fluorite phase [23]. In general, for Pb-based thin films (PZT or PLZT) the perovskite phase grows from the bottom electrode towards the bulk of the film while the fluorite (or pyrochlore) phase forms predominantly on the film surface [18], and sometimes a larger packet of fluorite penetrates some hundred nanometers through the film [25]. In the present work, however, our results show that the pyrochlore phase grows near the bottom electrode meanwhile a perovskite phase grows on the pyrochlore layer to form a 
pure perovskite at the film surface. Recent studies on PZT thin films prepared by the same route indicate the presence of a mixture of the pyrochlore and perovskite phases and that the amount of pyrochlore phase decreases from the surface to the bottom film-electrode interface meanwhile the PZT perovskite shows a compositional gradient leading to changes from a Ti-rich composition near the surface to a Zr-rich composition near the film-electrode interface [26]. Although we have clear indications that the pyrochlore phase forms on the bottom electrode for PLZT thin films prepared from $\mathrm{Pb}$-stoichiometric solution, suggesting that nucleation starts on the Pt substrate, the mechanisms responsible for the phase transformations leading to random orientation in these films are not completely understood at this moment.

To compensate the $\mathrm{Pb}$-deficiency, due to $\mathrm{PbO}$ volatilization or $\mathrm{Pb}$ deviation from stoichiometry associated to $\mathrm{Pb}$ diffusion into the substrate, as the probable origin of the pyrochlore phase formation observed in PLZT films prepared from $\mathrm{Pb}$-stoichiometric solution, 20\% excess $\mathrm{Pb}$ precursor has been added to the starting solution of a new set of films. Fig. 2-a shows XRD patterns of PLZT thin films prepared from the solution with $20 \%$ excess $\mathrm{Pb}$, under a fix pyrolysis at $300{ }^{\circ} \mathrm{C}$ for 30 minutes and a final crystallization from $400{ }^{\circ} \mathrm{C}$ to $700{ }^{\circ} \mathrm{C}$ for 1 hour. In this figure the reflections $\mathrm{Pt}(111)$ and $\mathrm{Pt}(200)$ are attributed to the Pt substrate while the indexed $(h k l)$ peaks are associated to the PLZT perovskite. The XRD pattern of the film crystallized at $400{ }^{\circ} \mathrm{C}$ shows a typical characteristic of an amorphous material while a randomly oriented crystallization of the perovskite phase is observed for films crystallized between $500{ }^{\circ} \mathrm{C}$ and $700{ }^{\circ} \mathrm{C}$. The film crystallized at $700{ }^{\circ} \mathrm{C}$ better crystallizes, since the peaks associated to the perovskite phase become stronger and better defined at higher crystallization temperatures. No peaks associated to the pyrochlore phase are observed for this new set of films. Therefore, the 
result shown in Fig. 2-a demonstrate that adding 20\% of $\mathrm{PbO}$ in excess lead to pyrochlorefree PLZT thin films.

Based on the results shown in Fig. 2-a, the pyrolysis at $300{ }^{\circ} \mathrm{C}$ for 30 minutes followed by a final crystallization at $700^{\circ} \mathrm{C}$ for 1 hour is established as the optimal conditions to prepare pyrochlore-free PLZT films. Then, films with different thicknesses have been also prepared with $20 \% \mathrm{~Pb}$ in excess, under pyrolysis at $300{ }^{\circ} \mathrm{C}$ for 30 minutes and a final crystallization at $700{ }^{\circ} \mathrm{C}$ for 1 hour. Fig. 2-b shows XRD patterns of these PLZT thin films with thicknesses ranging from 238 to $540 \mathrm{~nm}$. All these films are polycrystalline, randomly oriented and no pyrochlore phase is observed. Based on the peak intensities of the XRD patterns shown in Fig. 2-b, the degree of the $a$-axis orientation $\alpha=\sum I(h 00) / \sum I(h k l)$ can be calculated for films with different thickness. We find that $\alpha$ decay exponentially from 0.47 to 0.32 when the film thickness increases from 238 to $540 \mathrm{~nm}$. Although it is not visible in Fig. 2-b, in the range of thickness studied the degree of orientation shows a small (100)-orientation tendency with decreasing the film thickness. The microstrain $(\Delta d / d)$ of the PLZT films can be also evaluated from XRD data in Fig. 2-b. The obtained value increases almost linearly from $1.7 \times 10^{-3}$ to $3.9 \times 10^{-3}$ when the film thickness is increased from 280 to $540 \mathrm{~nm}$.

Fig. 3-a and 3-b shows the behavior of the microstrain $(\Delta d / d)$ and the crystallite size (D) as a function of glancing $\theta$ angle for PLZT films with 280, 410 and $550 \mathrm{~nm}$ in thickness. These parameters are calculated based on XRD patterns recorded at different glancing $\theta$ angle (not shown here). The analysis shown in Fig. 3 gives us a qualitative behavior of the microstrain and crystallite size in the depth profile of the films. These results demonstrate a non-uniform microstrain and crystallite size along the film thickness, 
where both $\Delta d / d$ and $D$ parameters increase from the bottom film-substrate interface to the top surface. The microstrain values $\left(3.0 \times 10^{-3} \leq \Delta d / d \leq 8.2 \times 10^{-3}\right)$ calculated along the film thickness in the present work are slightly larger than the values reported in the literature [27] for (100)-oriented PZT films $\left(\Delta d / d \sim 1.5 \times 10^{-3}\right.$ for film with $100 \mathrm{~nm}$ in thickness) but are similar to the values reported for polycrystalline PZT films [28]. However, the crystallite size evaluated in the film depth profile $(14 \leq D \leq 57 \mathrm{~nm})$ is lower than the one reported in the literature ( $\sim 90 \mathrm{~nm}$ for film with $270 \mathrm{~nm}$ in thickness) for PZT films prepared by rf-sputtering [29].

The AFM images in Fig. 4 show the morphology of PLZT films with different thickness. The surface of the films is dense, without cracks or voids. The average grain size is $504,548,542$ and $562 \mathrm{~nm}$ for films with 238, 352, 430 and $540 \mathrm{~nm}$ in thickness, respectively, while the roughness root-mean-square (RMS) values are 19, 21, 27 and 24 $\mathrm{nm}$. The average grain size is affected by a relative uncertainty on the order of $10 \%$ and the rms roughness by a relative uncertainty on the order of $5 \%$. Based on these results, we can conclude that the grain size and RMS roughness of the PLZT films are essentially constant within the thickness range studied. The topography shows also a polycrystalline aspect with slightly elongated grains of different size, while the surface morphology does not noticeably change with increasing the film thickness. However, in the literature, the morphology of thinner films $(\sim 50 \mathrm{~nm})$ is characterized by rounded grains in oriented PLZT thin films prepared by rf-sputtering, while for thicker films $(\sim 650 \mathrm{~nm})$ the grains tend to assume a triangular shape, a clear correlation between the changes in the surface topography is the preferential orientation on these films [30]. Excluding the possible effects due to the substrate, a large amount per deposition of material to be 
crystallized, the chemical route used in our case may lead to the formation of elongated grains observed.

Fig. 5 shows the UFM maps relative to the morphological images reported in Fig. 4. UFM is a technique implemented, while working in contact AFM, by applying a vertical sample displacement at a high frequency, off the cantilever resonances [16]. In other words, it is an experimental method that allows one to establish the tip indentation for a given load value while measuring the local morphology. In a UFM map, brighter regions correspond to lower indentation values and thus higher elastic moduli [17].

In Fig. 5, we observe that the grainy structure is heterogeneous in elasticity, independently from the number of layer depositions. This is in accordance with the morphological characteristics shown in Fig. 4. Indeed each grain presents a homogeneous contrast, whereas different grains show different elastic behavior. The observed homogeneity for a specific grain suggests an effective response of ferroelectric domains homogeneously oriented in the grain, where different grains might present different domain orientation. Each grain could behave as a single object that has different connectivity with the underlying film and the UFM image shows the elastic interaction of the interface between each grain and the underlying regions. In addition, the domain orientation inside the grains depends on the internal crystalline structure. As the biggest crystallite sizes in the studied PLZT films were $\sim 57 \mathrm{~nm}$ and the average grain size of these films is $504-562 \mathrm{~nm}$, each grain can hosts several crystallites that can lead to a complex internal crystalline structure leading to grains with different mechanical properties. Therefore, the existence of grains with different elastic properties, as shown in Fig. 5 for films with different thicknesses, is indicative of grains with different texture at the nanoscale leading to a randomly orientated structure at the macroscale, as observed by the XRD measurements. 


\section{Conclusions}

In summary, the present work investigates the structural, microstructural and elastic properties of PLZT thin films prepared by a polymeric chemical method. Contrary to other reports in the literature, the analyses in the present work for films with mixed-phase show that the pyrochlore phase crystallizes predominantly near the bottom film-electrode interface. Reducing the pyrolysis temperature and introducing a $\mathrm{PbO}$ excess in the precursor solution can thus lead to suppression of the pyrochlore phase in the films. Pyrochlore-free PLZT films show a non-uniform microstrain and crystallite size along the film thickness with a heterogeneous complex grainy structure leading to different elastic modulus at the nanoscale.

\section{Acknowledgements}

We would like to express our gratitude to the Brazilian and Italian agencies for their financial support (Bilateral CNPq-CNR Project: 490436/2011-0). A research grant from CNPq (Process number: 307607/2009-7) for E.B. Araújo is acknowledged. The financial support from FAPESP for laboratories infrastructure is also acknowledged.

\section{References}

[1] G. H. Haertling, Electro-optic ceramics and devices. In Electronic Ceramics; L. M. Levinson, Ed.; Marcel Dekker: New York, NY, USA, 1988.

[2] G. H. Haertling, Ferroelectrics 75, 25 (1987).

[3] C. S. Lynch, Acta Mater. 44, 4137 (1996). 
[4] G. H. Haertling, J. Am. Ceram. Soc. 82, 797 (1999).

[5] M. Miyake, J. F. Scott, X. J. Lou, F. D. Morrison, T. Nonaka, S. Motoyama, T. Tatsuta and O. Tsuji, J. Appl. Phys. 104, 064112 (2008).

[6] J. F. Scott and C. A. P. de Araujo, Science 246, 1400 (1989).

[7] R. Thapliya, Y. Okano, S. Nakamura, Journal of Lightwave Technology 21, 1820 (2003).

[8] F. Craciun, M. Dinescu, P. Verardi, N. Scarisoreanu, A. Moldovan, A. Purice, C. Galassi, Appl. Surf. Sci. 248, 329 (2005).

[9] M. A. Mohiddon and K. L. Yadav, J. Sol-Gel Sci. Technol. 49, 88 (2009).

[10] R. Singh, T. C. Goel, S. Chandra, Mat. Res. Bull. 43, 384 (2008).

[11] E. C. Lima and E. B. Araújo, Adv. Mater. Phys. Chem. 2, 178 (2012).

[12] G. L. Brennecka, C. M. Parish, B. A. Tuttle, L. N. Brewer and M. A. Rodriguez, Adv. Mater. 20, 1407 (2008).

[13] A. P. Wilkinson, J. S. Speck, A. K. Cheetham, Chem. Mater. 6, 750 (1994).

[14] M. Pechini, U.S. Pat. Nº 330 697, July 11 (1967).

[15] G. K. Williamson, W. H. Hall, Acta Mettallurgica 1, 22-31 (1953).

[16] O. Kolosov, K. Yamanaka, Japan J. of Appl. Phys. Part 2-Letters, 32, 8A, L1095 (1993).

[17] F. Dinelli, M. R. Castell, D. A. Ritchie, N. J. Mason, G. A. D. Briggs, O. Kolosov, Phil. Mag. A 2000, 80, 2299

[18] K.G. Brooks, I.M. Reaney, R. Klissurska, Y. Huang, L. Bursill, N. Setter, J. Mater. Res. 9, 2540 (1994).

[19] M. Mandeljc, B. Malič, M. Kosec, G. Dražič, Integ. Ferro. 46, 329 (2002). 
[20] G. L. Brennecka, B. A. Tuttle, J. Mater. Res. 22, 2868 (2007).

[21] S. Y. Chen, I. W. Chen. J. Am. Ceram. Soc. 81, 97 (1998).

[22] A. Wu, P. M. Vilarinho, I. Reaney, I. M. M. Salvado. Chem. Mater. 15, 1147 (2003).

[23] I. M. Reaney, D. V. Taylor, K. G. Brooks, J. Sol-Gel Sci. Technol. 13, 813 (1998).

[24] A. D. Polli, F. F. Lange, C. G. Levi, J. Am. Ceram. Soc. 83, 873 (2000).

[25] C. M. Parish, G. L. Brennecka, B. A. Tuttle, L. N. Brewer, J. Am. Ceram. Soc. 91, $3690(2008)$.

[26] E. C. Lima, E. B. Araújo, Adv. Mat. Phys. Chem. 2, 178 (2012).

[27] D. Kwon, B. Kim, B. G. Kim, C. H. Chang, J. Korean Phys. Soc. 55, L1327 (2009).

[28] J. Lappalainen, V. Lantto, J. Frantti, J. Hiltunen, Appl. Phys. Lett. 88, 252901 (2006).

[29] X. Y. Wen, J. Yu, Y. B. Wang, W. L. Zhou, J. X. Gao, J. Appl. Phys. 108, 114103 (2010).

[30] A. Ferri, S. Saitzek, A. Da Costa, R. Desfeux, G. Leclerc, R. Bouregba, G. Poullain. Surface Science 602, 1987 (2008). 


\section{Figures captions}

Fig. 1: Grazing incidence XRD patterns (at a fix $\theta=13^{\circ}$ ) of PLZT thin films with $600 \mathrm{~nm}$ in thickness (prepared from $\mathrm{Pb}$-stoichiometric solution) pyrolyzed at $300^{\circ} \mathrm{C}$ (a), $350^{\circ} \mathrm{C}$ (b) and $400^{\circ} \mathrm{C}$ (c) for 30 minutes and crystallized at $700{ }^{\circ} \mathrm{C}$ for 1 hour. (d) XRD patterns at different glancing angle $\theta$ for PLZT film pyrolyzed at $400^{\circ} \mathrm{C}$ for 30 minutes and crystallized at $700{ }^{\circ} \mathrm{C}$ for 1 hour.

Fig. 2: XRD patterns $(\theta-2 \theta)$ of PLZT thin films prepared from $20 \%$ excess $\mathrm{Pb}$ resin for (a) films with $550 \mathrm{~nm}$ in thickness crystallized from 400 to $700{ }^{\circ} \mathrm{C}$ for 1 hour and (b) films with thicknesses ranging from 238 to $540 \mathrm{~nm}$ crystallized at $700{ }^{\circ} \mathrm{C}$ for 1 hour. All films have been pyrolyzed at $300{ }^{\circ} \mathrm{C}$ for 30 minutes.

Fig. 3: (a) Microstrain $(\Delta d / d)$ and (b) crystallite size $(D)$ as a function of different XRD grazing incidence angle for PLZT thin films with $540 \mathrm{~nm}$ (top), $430 \mathrm{~nm}$ (middle) and 352 $\mathrm{nm}$ (bottom) in thicknesses (t).

Fig. 4: AFM morphology images of PLZT films with (a) $238 \mathrm{~nm}$, (b) $352 \mathrm{~nm}$, (c) $430 \mathrm{~nm}$ and (d) $540 \mathrm{~nm}$ in thickness.

Fig. 5: UFM images of PLZT films with (a) $238 \mathrm{~nm}$, (b) $352 \mathrm{~nm}$, (c) $430 \mathrm{~nm}$ and (d) 540 $\mathrm{nm}$ in thickness. 


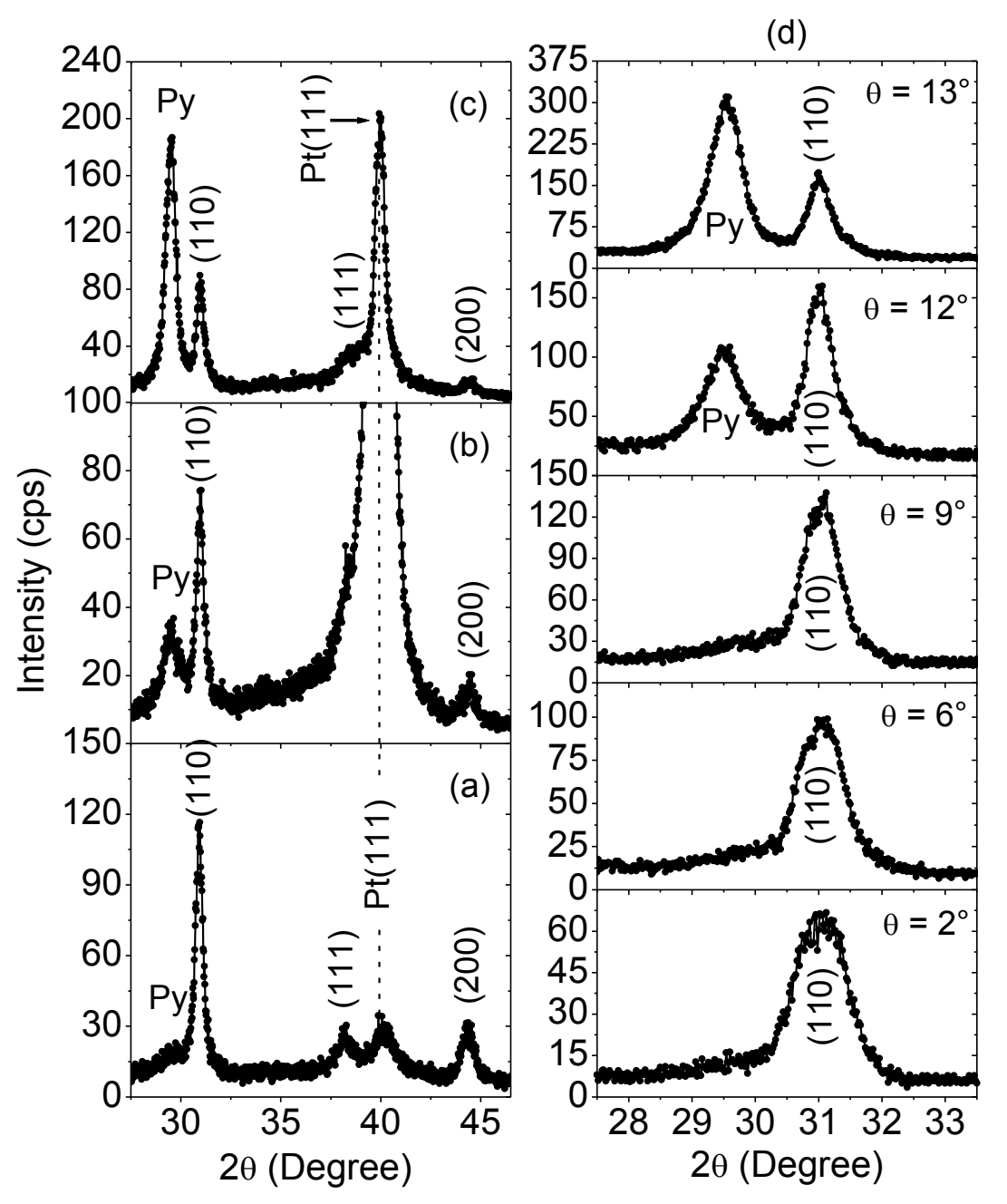

Fig. 1: E. B. Araújo et al. 
(a)

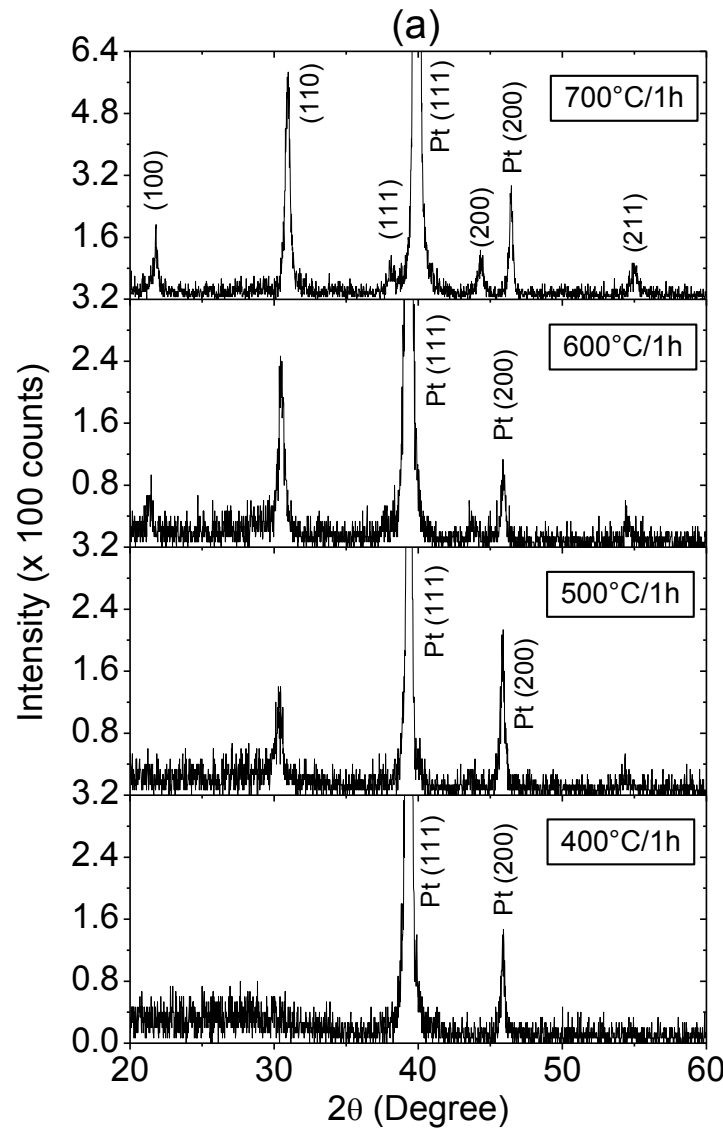

(b)

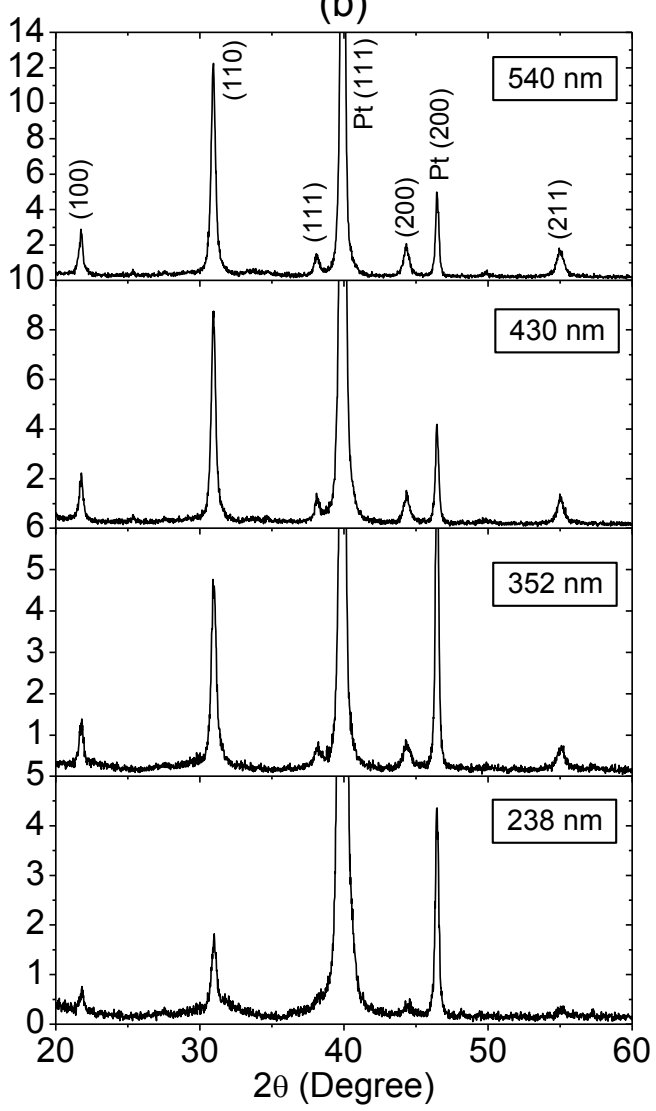

Fig. 2: E. B. Araújo et al. 
(a)

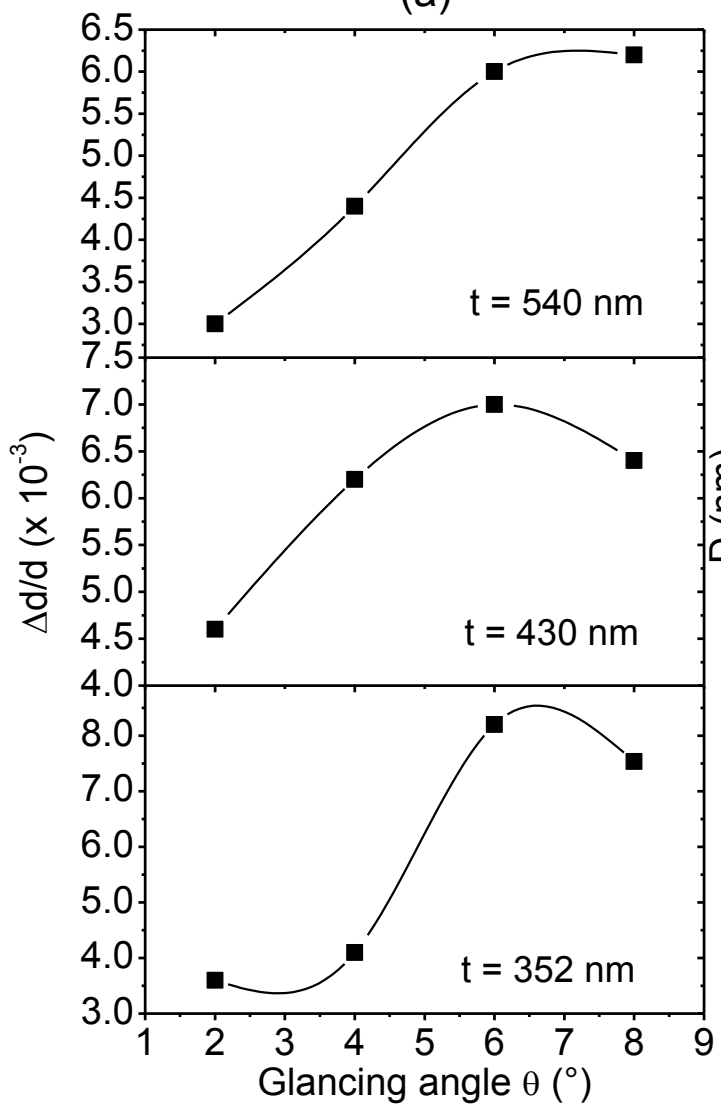

(b)

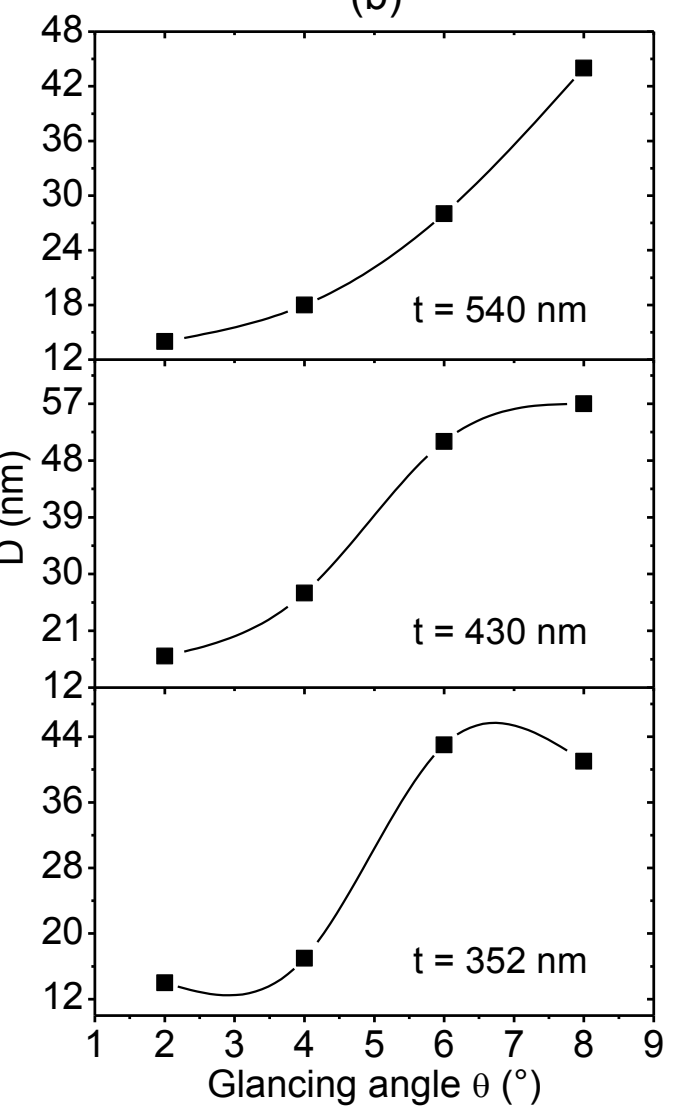

Fig. 3: E. B. Araújo et al. 

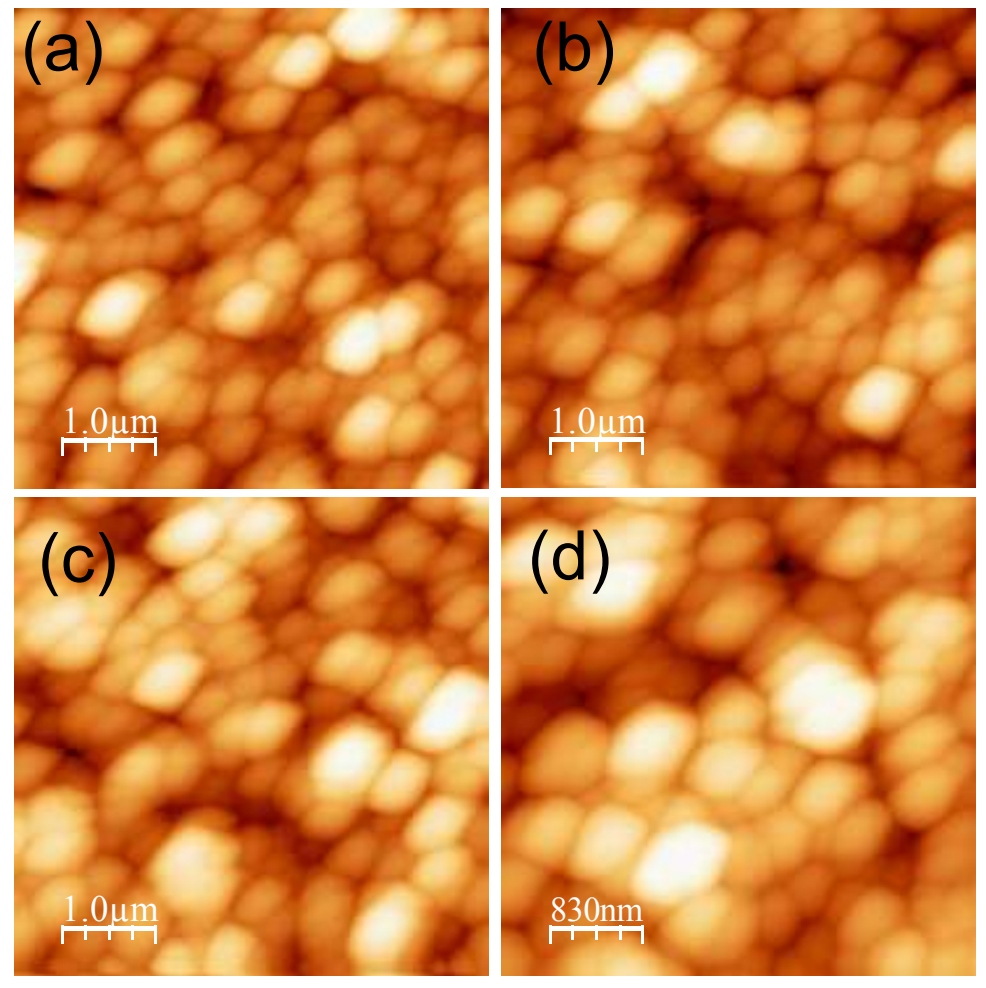

Fig. 4: E. B. Araújo et al. 


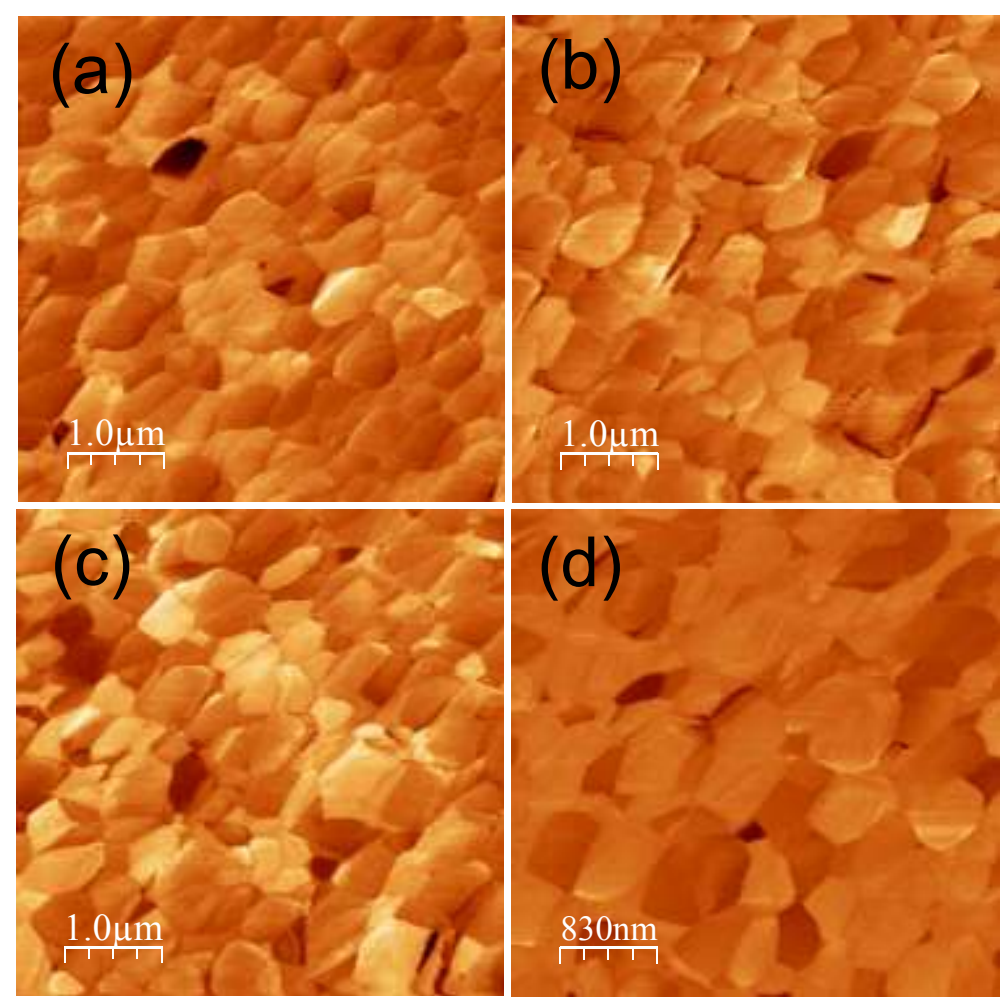

Fig. 5: E. B. Araújo et al. 